\title{
FATORES QUE FAVORECERAM A PERMANÊNCIA DAS ALUNAS NO PROGRAMA MULHERES MIL DO IFES CÂMPUS VITÓRIA: INTERAÇÕES E SUBJETIVIDADES
}

\author{
Jéssica Rubia Stein, Bianca Silva Santana, Ilda Regina Ribeiro de Oliveira, Juliana Celin \\ Fracaroli, Leidemacia Clementina de Souza Fonseca
}

Instituto Federal de Educação, Ciência e Tecnologia do Espírito Santo, câmpus Vitória

Vitória, Espírito Santo

E-mail: jessicarubia.lq@gmail.com, bianca0193@hotmail.com, ilda_fjo@hotmail.com, julianacelin@hotmail.com,

lleideju@gmail.com

Resumo: O artigo em tela refere-se ao Programa Mulheres Mil e ao público que este programa atendeu desde sua implementação, em 2012, no Ifes, câmpus Vitória. Busca analisar o Programa Mulheres Mil como uma política educacional adotada com objetivo de diminuir as diferenças e disparidades existentes entre homens e mulheres na sociedade patriarcal brasileira. Trata, assim, de políticas educacionais, relação de gêneros e empoderamento feminino. Explicita as características das duas primeiras turmas acolhidas pelo Programa no Ifes. Por fim, pontua os fatores que levam à permanência das alunas na instituição e ao êxito de tal política educacional.

Palavras-chave: Mulheres Mil, política educacional, empoderamento.

\section{FACTORS WICH FAVOURED THE PERMANENCE OF “THOUSAND WOMEN" PROGRAM'S STUDENTS IN IFES, CAMPUS VITÓRIA:INTERACTIONS AND SUBJECTIVITIES}

\begin{abstract}
The article in screen refers to the Thousand Women Program and the public who attended this program since its inception in 2012, in Ifes campus Victoria. The article analyzes the Thousand Women Program as an educational policy adopted to reduce the differences and disparities between men and women in Brazilian patriarchal society. It is about educational policies, gender relations and women's empowerment. The article also explains the characteristics of the first two groups received by the Program in Ifes. Finally, it highlights the factors that lead to the permanence of the students in the institution and to the success of this educational policy.
\end{abstract}

Keywords: Thousand Women, educational policy, empowerment.

Recebido em 24/08/2015. Publicado em 30/09/2016. 


\section{INTRODUÇÃO}

Historicamente, a sociedade brasileira foi organizada a partir de um modelo patriarcal, em que as mulheres eram designadas à procriação ou a seguir a vida religiosa. Gradualmente elas conquistaram espaços importantes na sociedade e muito embora tenham alcançado vitórias significativas - entre elas: o direito ao voto, o acesso à universidade e a possibilidade de exercer profissões predominantemente masculinas -, a realidade da mulher na sociedade ainda é pautada na desigualdade, especialmente no âmbito social e econômico.

Infelizmente, em nossa sociedade as mulheres são colocadas em uma posição inferior à do homem, sendo vítimas de um verdadeiro preconceito social, que fomenta a violência doméstica e a persistência da discriminação e da opressão ao gênero. Nas relações de trabalho, o público feminino é sujeitado a uma excessiva carga de responsabilidade, reforçada pela dupla jornada de trabalho: o doméstico e o remunerado. Além disso, não há equiparação salarial entre homens e mulheres.

Com o objetivo de amenizar as disparidades enfrentadas pela população feminina, o Governo Federal tem desenvolvido políticas públicas que almejam a inclusão, a equidade de gênero e a emancipação das mulheres pelo acesso à educação e ao universo do trabalho. Nesse contexto, pensou-se o Programa Nacional Mulheres Mil, que é parte do Plano Brasil sem Miséria. Advindo de uma parceria entre o Canadá e o Brasil, o programa tornou-se uma forma de cumprir as Metas do Milênio, estabelecidas pela ONU.

O Programa Nacional Mulheres Mil atende a mulheres maiores de 18 anos, em situação de vulnerabilidade social, com baixo nível de escolaridade e moradoras de comunidades com baixo índice de desenvolvimento humano. Ele consiste em uma parceria entre a escola e a comunidade, visando a suprir as demandas desta através da reinserção da mulher no contexto escolar, por meio de um curso de qualificação.

No Brasil, as atividades tiveram início em 2007 com mil mulheres de 13 estados do Norte e Nordeste, sob a responsabilidade da Rede Federal de Educação Profissional e Tecnológica. No ano de 2012, promoveu-se a expansão do Programa para todos os Institutos Federais de Educação Tecnológica (IF) dos estados brasileiros, estando presente hoje nas 27 unidades da federação. Aderindo a essa proposta, o Instituto Federal do Espírito Santo (Ifes), câmpus Vitória, implantou, 
no segundo semestre de 2012, o Programa Mulheres Mil. Desde então, foram recebidos na instituição três grupos de mulheres atendidos pelo Programa. Aos dois primeiros grupos, foi ofertado o curso de "Gestão e Relacionamento com os Clientes", enquanto ao segundo grupo foi ofertado o curso de "Recepcionista".

No câmpus Vitória do Ifes, o programa Mulheres Mil está diretamente relacionado ao PROEJA, ambos responsáveis por tentar amenizar a dívida histórica com os desvalidos da sorte. Os jovens e adultos, mulheres e homens, negros, pardos e mestiços, que foram privados da escolarização na época adequada e permaneceram um longo período à margem da cidadania, ao terem sido negligenciados, podem, por meio dessas ações afirmativas, retomar as esperanças de integrarem ativamente a sociedade na qual estão inseridos.

A equipe de professores envolvida no Programa Mulheres Mil também atua nos cursos de licenciatura e de Educação para Jovens e Adultos oferecidos no Instituto. Assim, nós, alunos da Licenciatura em Letras/Português, durante todo o curso, acompanhamos a realidade do Programa por meio da perspectiva desses profissionais. Daí o interesse em entender melhor como se deu a implementação dessa política pública, numa perspectiva de pedagogia social, e verificar como ela influencia o exercício dos profissionais que se dispõem a colocá-la em prática.

Sabendo das dificuldades enfrentadas cotidianamente por esse público, vários alunos da instituição já se debruçaram sobre esse tema para desenvolver trabalhos de pesquisa. Este artigo, especificamente, pretende comparar os dois primeiros grupos atendidos pelo Programa, a fim de explicitar os fatores que favoreceram a permanência das alunas no Programa Mulheres Mil do Ifes, câmpus Vitória.

Para analisar o desenvolvimento do Programa Mulheres Mil no Ifes, primeiramente, será feita a caracterização dos grupos que foram eleitos como público alvo das ações. A primeira turma será mapeada a partir do questionário socioeconômico respondido pelas participantes ao ingressarem no curso e a partir de pesquisas e levantamentos já realizados pela coordenação do Programa, sistematizados no artigo intitulado "O Programa Mulheres Mil no Ifes campus Vitória: a experiência com as paneleiras de Goiabeiras" (MORAIS, SCOPEL, FERREIRA, 2014). 
Ainda não se conhece um trabalho que trate especificamente da segunda turma, assim, o perfil desse grupo será traçado com base no questionário socioeconômico também respondido pelas alunas quando ingressaram no curso. Além disso, será feita uma pesquisa de campo, utilizando-se as técnicas de questionário e entrevista, com alunas egressas do curso e com gestores do Programa, com o objetivo de averiguar a eficácia de sua implementação.

A terceira turma, anteriormente citada, foi fruto de uma integração entre o PRONATEC e o Programa Mulheres Mil e, por não cumprir apenas as especificidades do Programa, não será analisada por este artigo. Dessa forma, esta investigação assumirá uma abordagem qualitativa e comparativa, visto que pretende-se analisar os resultados alcançados com os grupos em questão, destacando os motivos que favoreceram ou não o sucesso do curso ofertado e a permanência das alunas no Programa.

Será feito um estudo do Ciclo de Políticas de Ball, a fim de entender o que leva ao sucesso ou ao fracasso de uma Política. Depois, serão analisadas as duas primeiras turmas do Programa Mulheres Mil no Ifes, câmpus Vitória, de forma a compreender as características gerais dos grupos. Em seguida, serão comparadas as características das duas turmas. Num terceiro momento, será feita uma análise dos fatores que levaram ao sucesso da primeira turma, que fez com que fossem ofertados cursos para outras turmas do Programa. Ao mesmo tempo, busca-se verificar se tais fatores se fizeram presentes também na segunda turma, possibilitando a continuidade do Programa na instituição.

\section{REFERENCIAL TEÓRICO}

A fim de analisarmos o Programa Mulheres Mil como uma Política Pública eficiente, é necessário ter em mente o que forma uma política, quais os seus contextos e como se dá sua implementação. O Ciclo de Políticas é uma abordagem formulada pelo sociólogo Stephen Ball e colaboradores que vem sendo utilizada em vários países, por pesquisadores, para analisar o campo de políticas sociais e educacionais. O Ciclo de Políticas é um método para análise de políticas a fim de compreender como elas são formuladas e como são implementadas em diferentes contextos.

Mainardes (2006, p. 48), destaca a relevância do estudo do Ciclo de Políticas proposto por Ball, afirmando que "a reflexão sobre tal abordagem é bastante útil no contexto brasileiro uma vez que o campo de pesquisa em políticas educacionais no Brasil é relativamente novo". 
Ball propôs um ciclo constituído por cinco contextos: Contexto de Influência, Contexto da Produção de Textos, Contexto da Prática, Contexto dos Resultados e Contexto da Estratégia Política. Segundo Mainardes (2006, p. 50), os contextos estão interligados e apresentam lugares e grupos de interesse envolvendo disputas e embates.

O Contexto da Influência é aquele no qual os discursos políticos são construídos e se dá início às políticas públicas. É nesse contexto que os grupos de interesse e as redes sociais operam, buscando adquirir apoio para seus argumentos e legitimidade para seus conceitos e propostas de solução para os problemas sociais destacados. O discurso formado nesse contexto em alguns momentos recebe apoio e em outros é desafiado por princípios e argumentos mais amplos.

No Contexto da Influência, também há interferências globais e internacionais na formulação de políticas nacionais, podendo essas interferências serem entendidas pelo fluxo de ideias, por meio de redes políticas e sociais; pelo "empréstimo de ideias; pela venda de "soluções" no mercado político e acadêmico por grupos e indivíduos; pelo patrocínio e, algumas vezes, pela imposição de algumas soluções oferecidas por agências multilaterais como Banco Mundial, UNESCO, FMI, entre outros (MAINARDES, 2006, p. 52).

O Contexto de Produção de Textos é aquele em que os textos políticos são realizados e articulados com a linguagem do interesse público em geral. Nesse contexto, temos como arena os textos legais, oficiais e políticos, comentários formais ou informais sobre estes; pronunciamentos; vídeos; panfletos e revistas. Os textos são resultado de disputas e acordos entre políticos. Os grupos de interesses são: políticos que desejam controlar a representação política.

O Contexto da Prática é o momento em que as respostas aos textos políticos produzidos têm consequências e são vivenciadas. Nesse contexto, a política está sujeita à interpretação e recriação podendo representar mudanças e transformações significativas na política original.

O quarto contexto - Contexto dos Resultados ou Efeitos - volta-se para as questões de justiça, igualdade e liberdade individual e para a ideia de que as políticas têm efeitos de primeira ordem, quando referem-se a mudanças na prática ou na estrutura, e de segunda ordem, quando o impacto dessas mudanças interfere nos padrões de cesso social, oportunidade e justiça social. 
O último contexto é o Contexto de Estratégia Política. Esse contexto busca identificar atividades sociais e políticas que seriam necessárias para lidar com as desigualdades criadas ou reproduzidas pela política investigada.

Segundo Mainardes (2006, p. 55-58)

A abordagem do ciclo de políticas traz várias contribuições para a análise de políticas, uma vez que o processo político é entendido como multifacetado e dialético, necessitando articular as perspectivas macro e micro. [...] Uma das vantagens dessa abordagem é a sua flexibilidade, uma vez que é apresentada como uma proposta de natureza aberta e como um instrumento heurístico [...].

No artigo em tela enfatizaremos quatro dos cinco contextos que compõe o ciclo de políticas de Ball: o contexto da influência, o contexto da produção de textos, o contexto da prática e o contexto dos resultados.

\section{CONTEXTO DE PRODUÇÃO TEXTUAL}

O Programa Nacional Mulheres Mil - Educação, Cidadania e Desenvolvimento Sustentável é recente, foi instituído pela Portaria n. 1.015, de 21 de julho de 2011, que regulamenta e caracteriza o programa. Segundo o art. $3^{\circ}$, o programa deve ser ofertado por instituições de educação profissional e tecnológica, permitindo a parceria com instituições de ensino regular. O inciso 2 do mesmo artigo informa que o programa pode ser ofertado por entidades privadas vinculadas ao "Sistema S".

De acordo com o texto da portaria, o Programa pode também ser ofertado na modalidade PROEJA, nos termos do decreto 5.840, de 24 de julho de 2006. Entre as diretrizes, o art. 20 destaca as principais: possibilitar o acesso à educação, contribuir para a redução de desigualdades sociais e econômicas de mulheres, promover a inclusão social, defender a igualdade de gênero e combater a violência contra a mulher.

O Mulheres Mil foi implantado na Rede Federal de Educação Profissional e Tecnológica em parceria com o Sistema de Faculdades e Institutos Canadenses, representados pela Associação das Faculdades Comunitárias Canadenses (ACCC), e os Institutos Federais, representado pela Secretaria de Educação Profissional e Tecnológica do Ministério da Educação (Setec-Mec). As 
ações do Programa são decorrentes de uma Cooperação Internacional entre Brasil e Canadá e visam a Promoção de Intercâmbio de Conhecimento para Promoção da Equidade (PIPE).

As metodologias utilizadas no Canadá foram repassadas para os institutos e adaptadas à realidade do Brasil. Paul Brennan, Vice-presidente da Associação dos Colleges Comunitários do Canadá (ACCC), em depoimento contido na publicação Mulheres Mil na Rede Federal - Caminhos da Inclusão (2011, p. 6), afirma que "abrir as portas dos Institutos Federais Tecnológicos brasileiros ou dos Colleges canadenses para as pessoas que são marginalizadas e já perderam a esperança é um dos desafios mais significativos que podemos ter em nossas vidas como educadores".

Como público alvo, buscam atender mulheres com mais de 18 anos, em situação "de baixa renda, vulneráveis socialmente e de baixo nível de escolaridade; moradoras de comunidades integrantes dos Territórios da Cidadania e/ou com baixo índice de desenvolvimento humano" (BRASIL, 2013, p. 2). A inclusão desse público é estimulada por meio do acesso à educação profissional e tecnológica, traduzida na oferta de cursos e programas de educação profissional, com carga horária mínima de 160 horas. Com isso, espera-se promover a inserção das egressas no mundo do trabalho, incentivando o empreendedorismo, as formas associativas e solidárias e a empregabilidade.

Além disso, o Programa almeja gerar impactos sociais, entre eles: a redução das desigualdades sociais, contribuindo para a erradicação da miséria no país; a melhoria dos índices da equidade e igualdade de gênero no Brasil; a redução dos índices de violência doméstica; a melhoria da renda familiar nas comunidades em situação de vulnerabilidade; o crescimento do desenvolvimento sustentável das comunidades beneficiadas, associado à conscientização do uso sustentável dos recursos naturais; a melhoria das relações familiares e comunitárias; e, a melhoria de índices educacionais na modalidade de educação de jovens e adultos, contribuindo também para a redução do analfabetismo (BRASIL, 2013). Portanto, o Programa tem como objetivo colaborar com a formação profissional e cidadã desse público, oferecendo subsídios para o empoderamento dessas mulheres.

Percebe-se que a legalização referente ao Programa Mulheres Mil ressalta a importância de se considerar as características das mulheres atendidas, bem como valorizar o conhecimento e as experiências das discentes, o que pode enriquecer o processo de ensino-aprendizagem da turma. 
O Guia Metodológico do sistema de Acesso, Permanência e Êxito apresenta como objetivos específicos "Ser instrumento de diálogo com a comunidade, permitindo o ingresso, de modo acolhedor e personalizado, da população feminina em situação de vulnerabilidade social nas instituições de educação profissional e tecnológica" e "Agregar valor ao processo de ingresso, reconhecendo a aprendizagem prévia das mulheres, respeitando sua trajetória de vida e sua construção social”. Portanto, percebe-se que a produção textual sobre o Programa Mulheres Mil destaca a importância de se compreender as especificidades do público-alvo e de se adotar uma pedagogia diferenciada como condições essenciais para o sucesso do curso.

\section{CONTEXTO DA PRÁTICA}

\subsection{Caracterização da primeira turma do Mulheres Mil no Ifes, câmpus Vitória}

Para promover a implementação do Programa, o Ifes elegeu a comunidade onde residem as paneleiras de Goiabeiras como público alvo para a primeira turma. A produção artesanal de panelas de barro é uma atividade majoritariamente feminina, tradicional na região de Goiabeiras Velha, em Vitória, Espírito Santo. A técnica para a confecção tem origem indígena e é transmitida de mãe para filha, conservando a identidade cultural desse ofício de geração em geração.

Após identificar as demandas da comunidade, a Instituição, por meio do Programa Mulheres Mil, ofereceu o curso de qualificação "Gestão e Relacionamento com os Clientes", com início no segundo semestre de 2012 e carga horária total de 160 horas divididas em dois encontros semanais. As disciplinas foram pensadas com objetivo de agregar valor ao trabalho artesanal já exercido pelas paneleiras e contribuir para a formação cidadã; foram elas Português, Matemática, Informática, Inglês, Espanhol, Relações no trabalho e Economia solidária.

Para delinear o perfil das alunas participantes da primeira turma, analisamos os levantamentos esquematizados pela coordenação do Programa e os dados fornecidos pelo sistema acadêmico do Ifes. A partir deles, notou-se que a faixa etária das discentes concentrava-se acima dos 30 anos de idade, tendo, inclusive, mulheres com mais de 80 anos, conforme demonstrado no gráfico abaixo. 
Gráfico 1. Faixa etária das alunas da 1ạ turma.

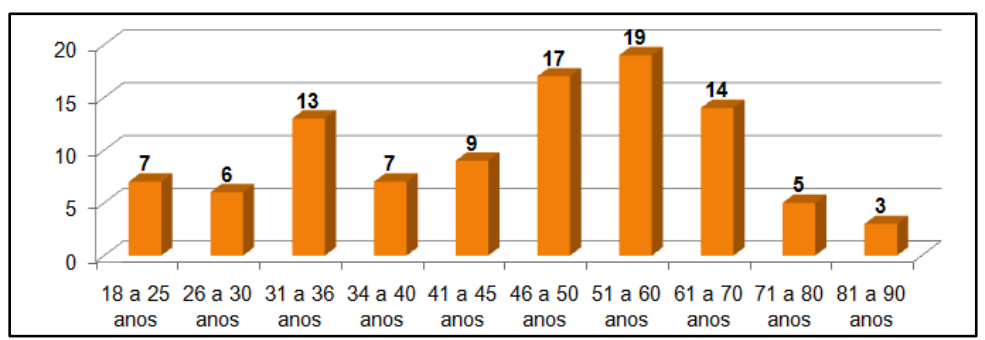

Fonte: Sistema acadêmico Ifes/2015. Elaborado pelas autoras.

Ao responderem o questionário socioeconômico, 91\% das ingressantes se autodeclararam negras ou pardas, o que reafirma a ligação existente entre as questões étnico-raciais, a disparidade entre gêneros e a situação de vulnerabilidade social.

Gráfico 2. Autoproclamação étnico-racial da 1ạ turma.

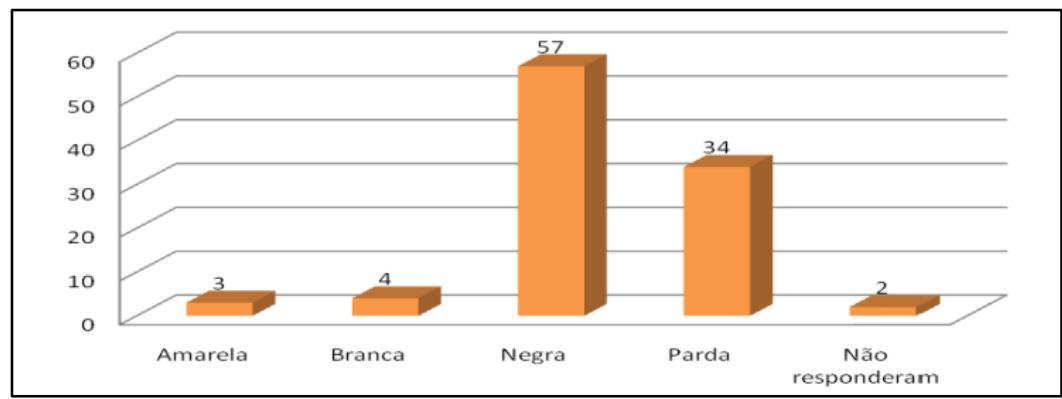

Fonte: MORAIS, SCOPEL, FERREIRA, 2014, p. 13.

O grau de escolaridade é outro dado relevante para traçarmos o perfil da primeira turma do Programa. Visto que não há a exigência de determinado nível de escolaridade para ingressar no curso, as alunas matriculadas atendiam a diferentes categorias, do grau de analfabetismo ao curso superior, como elucidado no gráfico a seguir. 
Gráfico 3. Grau de escolaridade da 1a turma.

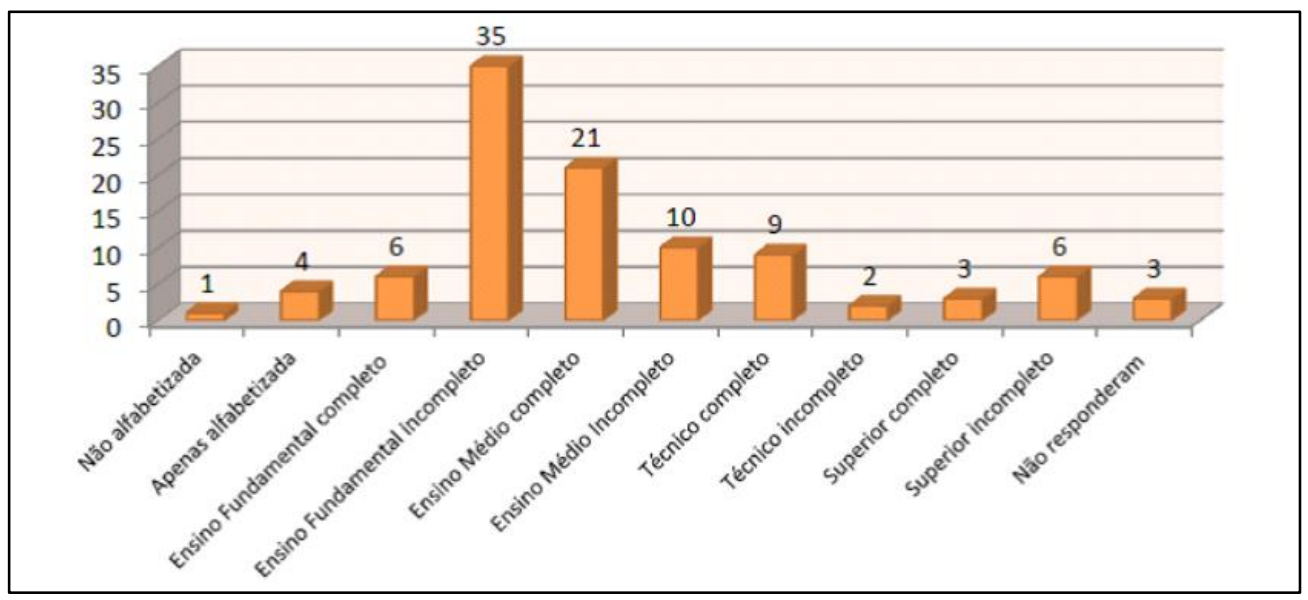

Fonte: MORAIS, SCOPEL, FERREIRA, 2014, p. 13.

Diante desses dados, percebe-se que a turma formada pelas paneleiras era bastante heterogênea, especialmente no que diz respeito à escolaridade. Em contrapartida, o fato de pertencerem à mesma comunidade e exercerem a mesma atividade laboral contribuiu para a unidade do grupo.

No âmbito escolar, coube aos professores e à equipe pedagógica sistematizar os conteúdos de maneira com que todas as alunas fossem envolvidas. Vale ressaltar que professores e demais profissionais, são fundamentais no contexto das práticas, uma vez que "exercem um papel ativo no processo de interpretação e reinterpretação das políticas educacionais e, dessa forma, o que eles pensam e no que acreditam têm implicações para o processo de implementação das políticas" (MAINARDES, 2006, p. 53).

Uma das estratégias utilizadas foi a de aproveitar os conhecimentos advindos da confecção das panelas de barro para nortear as discussões em sala, promovendo uma aproximação com a realidade das discentes. O depoimento de uma das coordenadoras do Programa no Instituto destaca que a prioridade era proporcionar a essas alunas um ambiente convidativo:

E há toda aquela questão do apoio pedagógico, do acolhimento a essas pessoas, porque esse é o principal papel. Então, para atender a elas, era toda uma leva [de pessoas]: eram alunos de iniciação científica, gente do pedagógico, coordenadores de curso... Tinha que ter todo um aparato, porque o Mulheres Mil tem esse foco do acolhimento, de você acolher a essa mulher em vulnerabilidade 
social, porque esse é um dos pré-requisitos (Edna Scopel, coordenadora e pedagoga do Programa Mulheres Mil, no Ifes, câmpus Vitória).

Essas estratégias foram bem recebidas pelas participantes do Programa, como podemos observar no relato abaixo, de uma aluna de 51 anos.

E esse curso abriu minha mente. Eu vi o modo como os professores estão ensinando para a gente aqui. Eu posso voltar a estudar. Eu fiquei mais corajosa para voltar para a escola. Eu vi que ainda posso fazer isso. Então, para mim está sendo muito bom. Matemática, Espanhol, Gestão... maravilha!!!. Estou apaixonada. Agora, estou pensando em voltar mesmo firme. Essa experiência está sendo ótima para minha vida. A minha mente não é como a de um adolescente. Não está mais veloz. Mas o professor está explicando de uma maneira que a gente está assimilando e aprendendo. Tudo está sendo muito bom para mim. Estou conseguindo saber que eu sei ainda. Está sendo uma experiência ótima. Estou pensando em voltar a estudar mesmo (apud MORAIS, SCOPEL, FERREIRA, 2014, p. 18).

O curso oferecido por meio do Programa Mulheres Mil, por ser profissionalizante, não promove a verticalização do ensino, isto é, as mulheres que possuem ensino fundamental incompleto continuarão com esse grau de escolaridade. Entretanto, o Programa despertou nas participantes o desejo e a coragem de voltar aos estudos.

Além disso, o Programa contribuiu para a melhoria do relacionamento familiar e comunitário, como salienta o depoimento de uma aluna de 42 anos.

[...] estamos conhecendo pessoas novas como vocês, os professores, a maioria das pessoas que tem na nossa sala são todas conhecidas porque são do meu bairro, não tinha intimidade, mas hoje em dia quando a gente passa na rua e se vê, dá um bom dia, um boa tarde e um boa noite. Antes passava uma de lá, outra de cá. Assim, só em questão do relacionamento que a gente está tendo mais umas com as outras, já conta bastante. Melhorou o relacionamento, a forma de falar e de se relacionar com as pessoas (apud MORAIS, SCOPEL, FERREIRA, 2014, p. 18). 
A primeira turma do Mulheres Mil ganhou destaque pela união entre as alunas, o que beneficiou o desenvolvimento das atividades em sala e favoreceu a permanência das educandas no curso, pois uma apoiava e incentivava a outra.

\subsection{Caracterização da segunda turma do Mulheres Mil no Ifes, câmpus Vitória}

A segunda turma teve um perfil distinto do da primeira. Para dar continuidade ao Programa, no segundo semestre de 2013, foram escolhidas como público alvo mulheres da região da llha das Caieiras e de São Pedro, ambos bairros da Grande Vitória, onde se destacam a atividade da pesca e da culinária feita com frutos do mar. O desfio de siris também é uma atividade típica da região. Esse ofício, na maioria das vezes, é exercido por mulheres e a tradição é repassada entre as gerações. As mulheres que praticam o desfio de siris podem realizar essa atividade de forma autônoma ou se filiarem à Cooperativa das desfiadeiras.

Ao contrário do que ocorreu com a primeira turma, a parceria entre o Instituto e a comunidade não teve tanto êxito, principalmente porque a Associação de Moradores não aderiu à ideia. Mesmo assim, a Instituição organizou uma equipe para divulgar o Programa na comunidade e convidar moradoras a participarem. Uma das exigências do Programa é que os grupos sejam formados por cem mulheres, e nessa comunidade apenas cinquenta realizaram a matrícula.

Para preencher as vagas restantes, o Ifes divulgou o curso na Escola Municipal de Educação de Jovens e Adultos Professor Doutor Admardo Serafim de Oliveira, localizada no município de Vitória, que atende alunos de toda a região da Grande Vitória, inclusive de outros municípios. Cinquenta alunas dessa escola realizaram a matrícula no curso, completando o total de vagas requisitado pelo Programa.

Formou-se então um grupo misto, composto pelas desfiadeiras de siri e pelas alunas da Escola Doutor Admardo Serafim de Oliveira. A esse segundo grupo foi oferecido o curso de qualificação "Gestão e Relacionamento com os Clientes", com mesma carga horária de 160 horas e matriz curricular.

O perfil das alunas da segunda turma foi traçado a partir de entrevistas realizadas com alunas egressas e dos questionários socioeconômicos respondidos pelas discentes no ato da matrícula. 
Foram disponibilizados pela coordenação do Programa apenas 67 questionários, de um total de 100, que correspondem à quantidade de alunas ingressantes.

A faixa etária das ingressantes, assim como na primeira turma, concentrava-se acima dos 30 anos de idade, como ilustra o gráfico seguinte.

Gráfico 1. Faixa etária das alunas da $2^{a}$ turma.

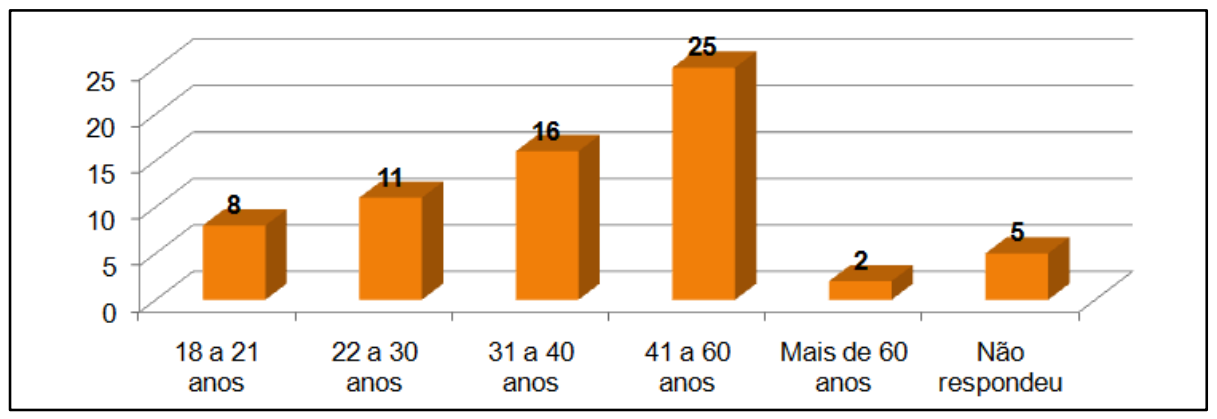

Fonte: Questionário socioeconômico respondido pelas alunas. Gráfico elaborado pelas autoras.

Quando perguntadas sobre sua raça/cor, aproximadamente $73 \%$ das alunas se autodeclararam negras ou pardas e $16 \%$ disseram se considerar brancas.

Gráfico 2. Autoproclamação étnico-racial da 2 a turma.

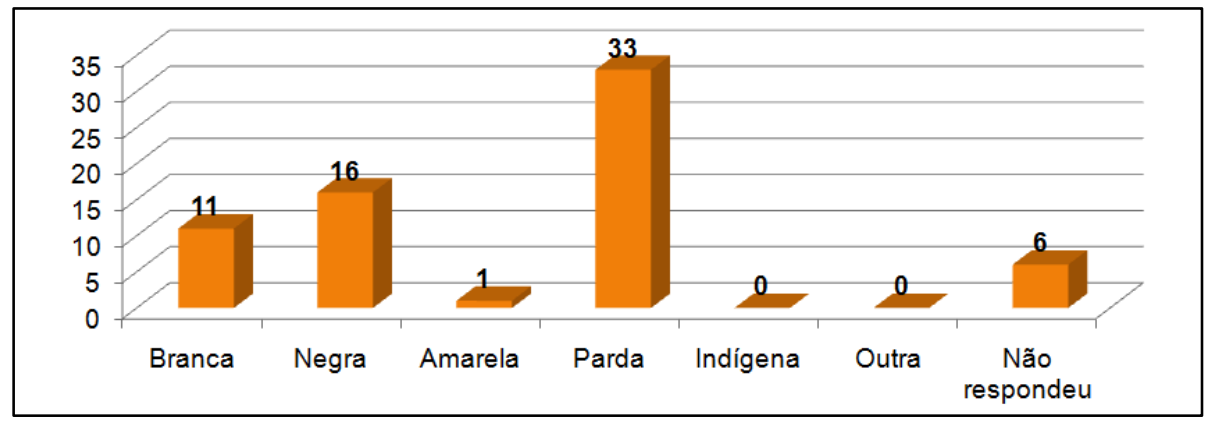

Fonte: Questionário socioeconômico respondido pelas alunas. Gráfico elaborado pelas autoras.

As alunas também foram questionadas sobre o grau de escolaridade que possuíam. Constatou-se que a grande maioria das educandas tinha Ensino Fundamental incompleto, sendo que parte delas estavam cursando esse nível de ensino na Escola Municipal de Educação de Jovens e Adultos Professor Doutor Admardo Serafim de Oliveira, instituição com a qual o Ifes firmou parceria. $O$ gráfico a seguir sistematiza os dados coletados: 
Gráfico 3. Grau de escolaridade da 2ª turma.

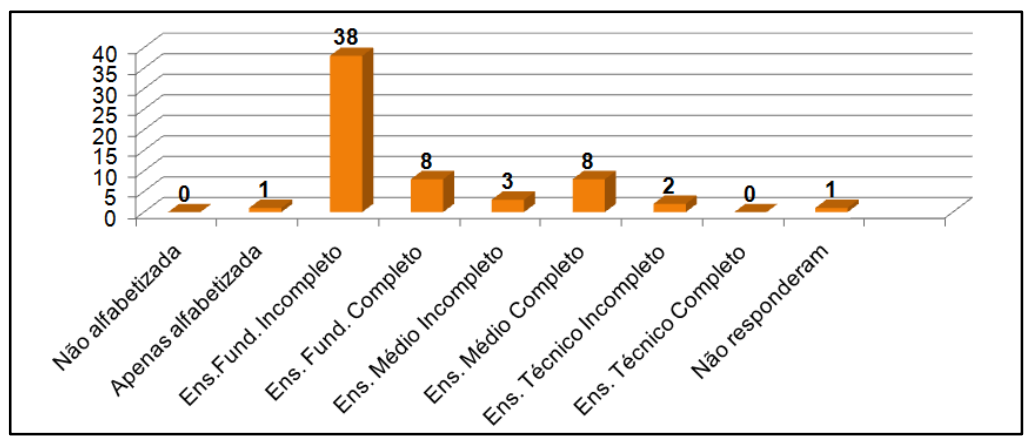

Fonte: Questionário socioeconômico respondido pelas alunas. Gráfico elaborado pelas autoras.

Esse grupo apresenta certa homogeneidade, se comparado com o público da primeira turma: a faixa etária e o grau de escolaridade das ingressantes são similares. Entretanto, o fato de não pertencerem à mesma comunidade, pode ter contribuído, ainda que indiretamente, para a não permanência das alunas no curso, como constatado no relato da coordenadora do Programa no Instituto:

Então 50\% [das alunas] eram da Ilha das caieiras e 50\% eram da Escola Admardo, que atende alunos do Ensino Fundamental de EJA. Só que a gente já percebeu uma evasão maior. Não houve esse envolvimento como houve no primeiro Mulheres Mil, mas a gente conseguiu, também, desenvolver um trabalho legal (Edna Scopel, coordenadora do Programa Mulheres Mil no Ifes, câmpus Vitória).

Embora tenham ocorrido desistências, há casos de discentes que decidiram dar prosseguimento aos estudos, como é o caso da aluna de 43 anos, egressa do Programa Mulheres Mil, que atualmente cursa o terceiro período do curso Técnico em Segurança do Trabalho Integrado Proeja.

Foi muito bom, porque eu tava há muito tempo fora da escola. E aí assim que eu vim fazer o curso aqui, foi bom porque o atendimento ao cliente melhorou muito, né, porque eu mexia muito com os moradores, pra escrever também, né? Entender informática, porque eu não tinha. Eu era porteira há muitos anos, não perdia o emprego, mas não tinha informática. E através desse curso aqui eu comecei a conhecer a informatização, e foi muito bom pra mim. [...] Eu tava com a autoestima muito baixa, querendo estudar e tinha medo... Aí quando eu cheguei aqui eu vi quanta coisa diferente e importante que a gente ia aprender. Então a 
autoestima foi á em cima. Eu falei 'Não, eu vou continuar!'(apud MORAIS; SCOPEL; FERREIRA, 2014, p. 18).

Para essas mulheres, o retorno à escola e, em especial, ao Ifes, simbolizou a concretização de uma esperança: mais um degrau foi galgado na busca de novas formas e possibilidades de aprender, de se inserir no mundo do trabalho, de se reconhecer como sujeito de direito. Nesse sentido, o trabalho com a autoestima atua como facilitador, uma vez que proporciona às educandas possibilidades de tomar as rédeas de seu destino e desenvolver sua autonomia intelectual e política. Por fim, após analisar o contexto da prática do Programa Mulheres Mil, constatou-se que a emancipação humana, um dos objetivos centrais dessa política pública, está sendo alcançada.

\section{CONTEXTO DE RESULTADOS}

O Programa Mulheres Mil busca atender um público que historicamente está à margem do contexto social. As diferenças e desigualdades entre homens e mulheres são sabidamente legitimadas e incentivadas pela sociedade patriarcal que vivenciamos no Brasil. Essas diferenças são percebidas nos contextos familiar, escolar e trabalhista, entre outros, sendo construídas e reproduzidas pela sociedade, não biologicamente estabelecidas.

É importante ressaltar que a violência e a discriminação voltada à mulher ignoram fronteiras de classes sociais, de grau de industrialização, renda per capita, cultura, tecnologia, grau de instrução, política, entre outros quesitos. É necessário ainda acentuar que não se limita somente às classes menos favorecidas. O que se nota é que a divisão sexual do trabalho carrega consigo a persistência da segmentação e da remuneração diferenciada entre homens e mulheres, seja em países onde o capitalismo é subordinado ou avançado (FERREIRA; MORAIS; SCOPEL,2014, p. 8).

Nas últimas décadas, a partir das lutas dos movimentos feministas, percebeu-se uma mudança nas relações de gênero. Mudança esta intimamente relacionada ao processo de empoderamento das mulheres. Segundo Morais, Scopel e Ferreira (2014, p. 10), esse processo é facilitado pelas mudanças na educação, no acesso ao trabalho formal e remunerado, e pela representação política feminina. 
A opção pelo recorte de gênero dá-se pelo crescente número de mulheres que ampliam o seu papel na sociedade e em suas comunidades, assumindo a chefia das suas famílias, e que são responsáveis não só pelo sustento financeiro das suas residências, mas também pelo desenvolvimento cultural, social e educacional dos seus filhos e demais membros da família, fato que repercute nas futuras gerações e no desenvolvimento igualitário e justo do País (BRASIL, p. 5).

Ao mesmo tempo que é um tipo de Educação Profissional - uma educação formal, de qualificação profissional, ministrada em uma instituição de ensino-, o Programa pode ser analisado a partir da perspectiva da Pedagogia Social, que "se caracteriza como uma ciência transversal, aberta às necessidades populares, que busca enraizar-se na cultura dos povos para, dialeticamente, construir outras possibilidades sem aniquilar o passado, mas promover sua superação" (CHISTÉ, 2015, p. 1).

Se partirmos da ideia de que o ser humano é um ser social, e só se constitui como tal por meio da comunidade (CHISTÉ, 2015, p. 2), podemos admitir que a ação de Pedagogia Social é extremamente importante no que diz respeito à abordagem que será feita com os alunos, bem como às disciplinas que serão ofertadas. Isso porque o olhar pedagógico social vai partir não apenas do ambiente institucional escolar, mas também de ações educativas não formais alguma transformação política e social.

Com a integração entre a escola e a comunidade, busca-se atender às demandas específicas do público selecionado, de forma que as mulheres tenham uma qualificação na sua área de trabalho. No entanto, é preciso verificar até que ponto o programa atinge seu objetivo e contribui no âmbito social para a inclusão das mulheres na sociedade de direitos.

As turmas do programa, que frequentaram as aulas no Ifes, câmpus Vitória, foram acompanhadas de perto pela equipe pedagógica visando a fortalecer o lema "Acesso, Permanência e Êxito". Vale lembrar, entretanto, que não depende somente dos gestores. A garantia de acesso e permanência é feita através de diferentes ações conjuntas da equipe pedagógica, dos alunos bolsistas e de voluntários que participam do projeto. O êxito, portanto, só é possível a partir da soma de muitos fatores. 
A primeira turma participante do programa Mulheres Mil, no Ifes, segundo a pedagoga do Programa, Edna Scopel, foi baseada de fato no projeto original. Houve o mapeamento de uma comunidade, que tinha uma cooperativa de trabalho organizada. Isso possibilitou a elaboração de uma estratégia que atendesse a necessidade do grupo, favorecendo a integração do projeto pedagógico aos objetivos de trabalho que as alunas já exerciam.

O grupo atendido pela primeira turma era unido pela atividade laboral, pertenciam a uma mesma região e apresentavam faixa etária semelhante e majoritariamente superior aos 60 anos. 0 objetivo principal desse grupo era aprimorar as relações com os clientes que elas já atendiam. De acordo com Morais, Scopel e Ferreira (2014, p. 21), “a experiência coletiva e a circulação em espaços públicos colaboraram para o processo de emancipação e autonomia, dando maior visibilidade às suas atividades produtivas [...]".

A segunda turma do Mulheres Mil era originalmente baseada em outra comunidade que apresentava características semelhantes às da primeira turma. Suas integrantes atendiam ao conjunto de especificidades visadas pelo Programa, entre elas: pertencer a uma mesma região e/ou comunidade, exercer atividade laboral semelhante, possuir faixa etária semelhante. Essa "caracterização" do grupo tem como finalidade estabelecer uma maior conexão entre as alunas participantes do programa e favorecer a elaboração de uma proposta pedagógica coerente e objetiva. Porém, por diversos fatores - entre eles a falta de colaboração da Associação de Moradores da região -, não se conseguiu formar a segunda turma com o público alvo escolhido, sendo preciso encontrar alternativas para completar o número de vagas, o que resultou na formação de uma turma heterogênea.

Diante disso, não foi possível elaborar uma proposta pedagógica que atendesse as especificidades de um grupo unificado, dificultando em alguns aspectos as intervenções pedagógicas. Entretanto o programa continuou tendo como base as necessidades do público alvo "generalizado" - mulheres em situação de vulnerabilidade social -, ao qual o projeto atende em uma perspectiva de valorização, ressignificação e empoderamento. A proposta de acesso, permanência e êxito foi mantida e as interações foram se reestruturando de acordo com as vivências da turma.

Nesse aspecto a equipe pedagógica, alunos bolsistas, voluntários e professores foram fundamentais para o desenvolvimento do projeto, pois buscaram inúmeras alternativas para 
fortalecer a integração do grupo. Isso devido ao fato de que a turma era composta por alunas de diferentes regiões da cidade de Vitória, que desenvolviam diferentes atividades laborais e principalmente diferentes níveis de escolaridade. Com um grupo diversificado em objetivos e histórias de vida, o programa surpreendentemente se enriqueceu de possibilidades não esperadas e os resultados dessa turma são diferentes, porém tão satisfatórios quanto os da primeira turma.

\section{CONSIDERAÇÕES FINAIS: FATORES QUE FAVORECERAM A PERMANÊNCIA DAS ALUNAS}

Ao analisarmos os contextos de prática e de resultados da implantação do Programa Mulheres Mil no Ifes, câmpus Vitória, pudemos perceber que existiram peculiaridades no perfil das alunas do Programa. Essas peculiaridades acabam por constituírem fatores que levaram à permanência na instituição e ao êxito do programa.

Ao entrarem em contato com um universo diferente do que elas tinham acesso até aquele momento, por meio da inserção no instituto, da participação nas aulas e nas palestras, as perspectivas dessas mulheres foram se transformando e modificaram também a forma como elas se reconheciam.

Na medida em que essas mulheres conseguem transitar e marcar seus espaços com o seu trabalho e modo de ser, passam a se "re-conhecerem" como sujeitos ativos/as, capazes de mudanças, de conquistas e vão encontrando formas de superar a violência e a dominação a quais estão submetidas(MORAIS; SCOPEL; FERREIRA, 2014, p. 20).

Ao participarem do projeto, as mulheres puderam se reconhecer como parte integrante da sociedade. Por meio do programa elas tiveram acesso ao debate de temas como saúde da mulher, economia solidária, entre outros assuntos relevantes, sempre acompanhadas por profissionais da área.

Analisando os grupos atendidos pelas turmas do Mulheres Mil, podemos dizer que diferentes fatores levaram ao acesso, à permanência e ao êxito das alunas na instituição. Pode-se dizer também, a partir do contexto de resultados presente na perspectiva de análise de políticas públicas do Ball, que tais fatores são uma extensão da prática e, dessa forma, precisam ser evidenciados. Esses resultados, ainda na perspectiva de Ball, correspondem aos de primeira e 
segunda ordem, uma vez que estão diretamente ligados às ações da equipe de professores e da organização pedagógica, bem como estão relacionados ao aprendizado e ao desenvolvimento das alunas.

Dessa forma, observamos que os principais fatores favoráveis para esses grupos foram: o acolhimento e preparo do grupo pedagógico, adequação das práticas educacionais à realidade das alunas, o estímulo da autoestima, a possibilidade de se reconhecerem como sujeitos de direitos, a inserção em ambientes públicos, entre outros. Tais fatores foram fundamentais para o sucesso do programa nas turmas analisadas. Para além das interações, outros fatores subjetivos aos grupos atendidos foram relevantes para o desenvolvimento do programa e principalmente para o empoderamento das mulheres, pois "as conquistas obtidas propiciaram à mulher, categoria submetida a contextos de exclusão pela classe dominante masculina, instrumentos de poder na luta por maior autonomia" (MORAIS; SCOPEL; FERREIRA, 2014, p. 9).

À guisa de conclusão, podemos dizer, então, que o artigo contribui com o contexto da estratégia política de Ball, uma vez que por meio dele pode-se identificar as atividades sociais e políticas necessárias para lidar com as desigualdades criadas ou reproduzidas pelo Programa Mulheres Mil e, desta forma, melhorar as condições para o acolhimento das próximas turmas do Programa.

\section{AGRADECIMENTOS}

Aproveitamos a oportunidade para agradecer aos alunos e professores que colaboraram com a pesquisa, pelos relatos sinceros sobre a política pública em análise; à Coordenação do Programa Mulheres Mil no Ifes, câmpus Vitória - especialmente Maria José Ferreira Resende, Edna Scopel e Ana Lígia Oliveira Teixeira - por fornecerem informações valiosas para o desenvolvimento deste trabalho; e à nossa professora Dra. Priscila Chisté, pelo carinho e empenho ao nos guiar por essa jornada.

\section{REFERÊNCIAS}

BRASIL. Programa nacional mulheres mil: Educação, Cidadania e Desenvolvimento Sustentável. 2013. Disponível em: <http://portal.mec.gov.br/index.php?option=com_docman\&task=doc_download\&gid=8598\&ltemid=>. Acesso em: 21 jul. 2015. Acesso, Mulheres mil: Educação, Cidadania e Desenvolvimento Sustentável. Guia Metodológico do Sistema de permanência

e
Disponível

em: 
<http://portal.mec.gov.br/index.php?option=com_content\&view=article\&id=12299\&ltemid=603> Acesso em: 17 ago. 2015.

Mulheres Mil na Rede Federal: Caminhos de Inclusão. 2011. Disponível em: <http://mulheresmil.mec.gov.br/central-de-entrevistas/1679-mulheres-mil-na-rede-federal-caminhos-da-inclusao> Acesso em: 17 ago. 2015.

- Portal da Cidadania. Territórios da Cidadania. 2008. Disponível em: <http://www.territoriosdacidadania.gov.br/dot/rn/clubs/territriosrurais/one-community?page_num=

0>. Acesso em: 21 jul. 2015.

PORTARIA № 1.015, DE 21 DE JULHO DE 2011.Disponível em: <http://www.mds.gov.br/brasilsemmiseria/legislacao-2/legislacao/arquivos/portaria-mulheres-mil-n1015.pdf>. Acesso em: 03 ago 2015.

CHISTÉ, Priscila de Souza; CARVALHO, Letícia Queiroz de; FOERSTE, Erineu. Pedagogia Social e Educação Profissional: diálogos possíveis? In: Pedagogia Social em diálogo: educação profissional, linguagens e saberes do campo. No prelo, 2015.

MAINARDES, Jefferson. Abordagem do ciclo de políticas: uma contribuição para a análise de políticas educacionais. Campinas, vol. 27, n. 94, p. 47-69, jan./abr. $2006 . \quad$ Disponível em: <https://bay172.mail.live.com/mail/ViewOfficePreview.aspx?messageid=mgPFZKDrLu5BGV3NidZ1x5gA2\&folderid=fli nbox\&attindex $=11 \& c p=-1 \&$ attdepth=11\&n=34712405>. Acesso em: 03 ago. 2015 .

MORAIS, Érica Renata Vilela. SCOPEL, Edna Graça. FERREIRA, Maria José de Resende. O Programa Mulheres Mil no IFES campus Vitória: a experiência com as paneleiras de Goiabeiras. 2014. Disponível em: <http://www.senept.cefetmg.br/galerias/Anais_2014/GT09/GT_09_x5x.PDF>. Acesso em: 21 jul. 2015. 